\title{
Analisis Akar Penyebab Masalah Dalam Meningkatkan Overall Equipment Effectiveness (OEE) Mesin Pengisi Krim ke Tube PT. Kimia Farma Plant Watudakon
}

\author{
M. Fithrul Mubarok ${ }^{1,2}$, Hadi Kardoko ${ }^{2}$, dan Agnes Nuniek Winantari ${ }^{3}$
}

\author{
${ }^{1}$ Program Studi Magister Farmasi, Universitas Surabaya, Surabaya \\ 2 PT. Kimia Farma Watudakon, Jombang \\ ${ }^{3}$ Departemen Farmasetika, Fakultas Farmasi Universitas Surabaya, Surabaya
}

Korespondensi: M. Fithrul Mubarok

Email: fithrul.mubarok23@gmail.com

Submitted: 02-12-2018, Revised: 15-04-2019, Accepted: 16-04-2019

\begin{abstract}
ABSTRAK: Industri farmasi Indonesia menghadapi tantangan besar dalam produktivitas dan efisiensi pada persaingan pasar yang kompetitif karena adanya program Jaminan Kesehatan Nasional dengan pengadaan melalui e-catalog. PT. Kimia Farma Plant Watudakon merupakan peserta pengadaan e-catalog sehingga dituntut untuk memberikan harga yang bersaing dengan kuantitas besar. PT. Kimia Farma Plant Watudakon dapat meningkatkan efisiensi mesin dengan perhitungan OEE (Overall Equipment Effectiveness) dan identifikasi komponennya. Penelitian ini bertujuan menghitung nilai OEE dan menganalisis enam kerugian besar dari dua mesin pengisi krim ke tube untuk produk unggulan krim mikonazol nitrat 2\%. Pengumpulan data dilakukan dengan metode observasional secara langsung di ruang produksi antara bulan Februari-Juli 2018. Hasil penelitian menunjukkan bahwa nilai OEE mesin pengisi krim ke tube I dan II berturut-turut adalah 73,38\% dan 73,82\%. Nilai OEE kedua mesin ini belum ideal, analisis Pareto menunjukkan bahwa idling and minor stoppages losses dan reduced speed losses merupakan penyebab terbesar kerugian yaitu 78,10\% untuk mesin pengisi krim ke tube I dan 78,84\% untuk mesin pengisi krim ke tube II. Berdasarkan analisis sebab akibat, akar masalah dari idling and minor stoppages losses dan reduced speed losses adalah tidak seragamnya keterampilan operator, pengaturan mesin yang kurang tepat, preventive maintenance kurang optimal dan penanganan tube aluminium yang tidak maksimal.
\end{abstract}

Kata kunci: industri farmasi; OEE; analisis Pareto; analisis sebab akibat; enam kerugian besar

\begin{abstract}
Indonesian pharmaceutical industry is facing a great challenge in the area of productivity and efficiency in current competitive market competition.This was induced by National Health Assurance program through drug procurement via e-catalog. PT. Kimia Farma Watudakon is e-catalog auction supplier for miconazole nitrate $2 \%$ cream generic drug as its mainstay drug product. Generic drug procurement with e-catalog wassettled with open-auction, which requires the pharmaceutical industry to offer not only competitive price but also the capability to produce a high quantity of the product. Pharmaceutical industry might increase its machine efficiency by means of OEE (Overall Equipment Effectiveness) calculation and the identification of its component. This study was aimed to calculate OEE value and analyze six big losses on two tubes filling machine for miconazole cream 2\%.Data collection was conducted by observational method directly in the production room between February-July 2018. The result showed that OEE value of tube filling machine I and II is 73.38\% and 73.82\%, respectively. OEE value of these two tube filling machines is not ideal, the Pareto analysis shows that idling and minor stoppages losses and reduced speed losses are the biggest causes of losses, i.e. $78.10 \%$ for the machine I and 78.84\% for the machine II. According to cause and effect analysis, the root cause of these losses was the lack of skill uniformity among operators, suboptimal machine settings, suboptimal preventive maintenance, and the aluminum tube handling was not maximal.
\end{abstract}

Keywords: pharmaceutical industry; OEE; Pareto analysis; cause and effect analysis; six big losses 


\section{Pendahuluan}

Industri farmasi sekarang ini dalam kondisi persaingan yang ketat antar perusahaan farmasi, khususnya untuk obat generik. Persaingan dipicu karena adanya program Jaminan Kesehatan Nasional (JKN) yang mulai diimplementasikan pada awal tahun 2014. Program JKN untuk pengadaan obat generik melalui tender e-catalog obat sehingga memaksa industri farmasi untuk memberikan harga yang kompetitif dengan kuantitas besar dalam rentang waktu dua tahun. Adanya persaingan harga yang kompetitif ini mengharuskan industri farmasi untuk menjalankan operasional pabrik seefisien mungkin agar menghasilkan obat dengan biaya sekecil mungkin dan tetap mempertahankan kualitas.

Agar dapat bertahan pada persaingan yang ketat ini, industri farmasi harus melakukan perbaikan secara berkelanjutan dan meningkatkan efektivitas. PT. Kimia Farma merupakan salah satu industri farmasi di Indonesia, salah satu kontribusi pendapatan andalannya adalah lini obat generik. Pertumbuhan obat generik yang selalu meningkat dari tahun ke tahun karena adanya JKN dan persaingan yang ketat, mendorong PT. Kimia Farma melakukan peningkatan kapasitas dan efisiensi produksi obat dalam memenuhi permintaan pasar. PT. Kimia Farma Plant Watudakon merupakan salah satu plant PT. Kimia Farma dengan produksi andalan adalah sediaan semisolid krim generik, krim mikonazol nitrat $2 \%$. Permintaan produksi krim generik mikonazol nitrat 2\% PT. Kimia Farma Watudakon selalu meningkat dari tahun ke tahun.

Berdasarkan laporan penyerahan tahunan, pada tahun 2016 permintaan krim generik mikonazol nitrat $2 \%$ sebesar 4 juta tube dan pada tahun 2017 mencapai 7 juta tube, meningkat hampir dua kali lipat [1,2]. Proyeksi tahun 2018 permintaan krim generik mikonazol nitrat 2\% mencapai 17 juta tube, meningkat lebih dari 2 kali lipat dari periode tahun 2017 [3]. Adanya peningkatan produksi krim generik mikonazol nitrat 2\% mengharuskan PT. Kimia Farma Watudakon melakukan berbagai upaya, salah satunya adalah efisiensi mesin-mesin produksi. Proses inti dari produksi krim generik mikonazol nitrat $2 \%$ adalah penimbangan bahan baku, pencampuran obat, pengemasan primer dan pengemasan sekunder. Selama ini produksi krim mikonazol nitrat $2 \%$ sangat tergantung dari proses pengemasan primer oleh dua mesin pengisi krim ke dalam tube. Oleh karena itu perlu dilakukan penghitungan efisiensi mesin pengisi krim ke tube untuk menjadi dasar peningkatan kapasitas produksi.

Terdapat beberapa metode penghitungan produktivitas mesin diantaranya adalah OEE (Overall Equipment Effectiveness), TEEP (Total Equipment Effectiveness Performance), OPE (Overall Performance Efficiency) dan OTE (Overall Throughput Efficiency). Konsep umum dalam menghitung produktivitas dan efisensi mesin adalah OEE. Keunggulan dari metode penghitungan produktivitas OEE adalah metode ini digunakan secara luas pada berbagai jenis manufaktur dibandingkan dengan metode OTE, OPE, ataupun TEEP. Keunggulan terbesar dari OEE adalah sederhana sekaligus komprehensif mengukur efisiensi internal peralatan dan diaplikasikan secara luas [4]. OEE juga merupakan cara efektif menganalisis efisiensi sebuah mesin tunggal atau sebuah sistem permesinan terintegrasi [5]. OEE menunjukkan kombinasi dari tingkat ketersediaan mesin, kinerja mesin, dan kualitas produk yang dihasilkan oleh mesin. Hal ini lebih lengkap bila dibandingkan dengan OPE yang hanya menghitung kinerja dan ketersediaan mesin tanpa memperhitungkan kualitas produk. Kondisi ideal peralatan mempunyai nilai OEE lebih dari $85 \%$, yang terdiri dari nilai ketersediaan lebih dari $90 \%$, nilai kinerja lebih dari $95 \%$, dan nilai kualitas produk lebih dari 99\% [6].

Sejauh pengetahuan penulis, belum ada studi yang berfokus pada pengukuran efektivitas mesin menggunakan OEE pada mesin pengisi krim tube pada industri farmasi. Lebih dari itu, masalah nyata pada industri farmasi Indonesia mendorong pentingnya untuk dilakukan studi ini. Hasil penelitian ini diharapkan dapat diaplikasikan pada pabrik farmasi dan dapat memberikan masukan pada manajemen puncak untuk menerap- 
kan penghitungan efektivitas mesin dengan OEE.

Penelitian ini dapat berkontribusi pada literatur dan teori praktis dengan cara sebagai berikut: (1) Penelitian ini berfokus pada perhitungan OEE dua mesin pengisi krim ke tube. Nilai OEE yang didapat dibandingkan dengan nilai ideal OEE; (2) Enam kerugian besar diindentifikasi pada dua mesin pengisi krim ke tube menggunakan analisis Pareto. Dengan ini dapat diketahui kerugian-kerugian dari efektivitas mesin yang timbul. Manager yang bekerja di industri farmasi dapat fokus kepada kerugian dominan dengan tujuan peningkatan produktivitas mesin; (3) Pencarian akar masalah pada kerugian-kerugian dominan diidentifikasi detail dengan analisa sebab akibat. Akhirnya dapat diusulkan perbaikan-perbaikan berdasarkan penyebab masalah kerugian-kerugian efektivitas untuk meningkatkan nilai OEE mesin pengisi krim ke tube.

\section{Metode}

\subsection{Gambaran produksi krim mikonazol nitrat $2 \%$}

Krim mikonazol nitrat $2 \%$ adalah sediaan semisolid yang diproduksi dengan beberapa tahapan yaitu penimbangan bahan-bahan, pencampuran, pengemasan primer ke dalam tube dan pengemasan sekunder ke dalam dus. Gambar 1 menunjukkan alur proses pembuatan krim mikonazol nitrat $2 \%$. Sediaan krim secara umum terdiri dari dua fase yaitu fase minyak dan fase

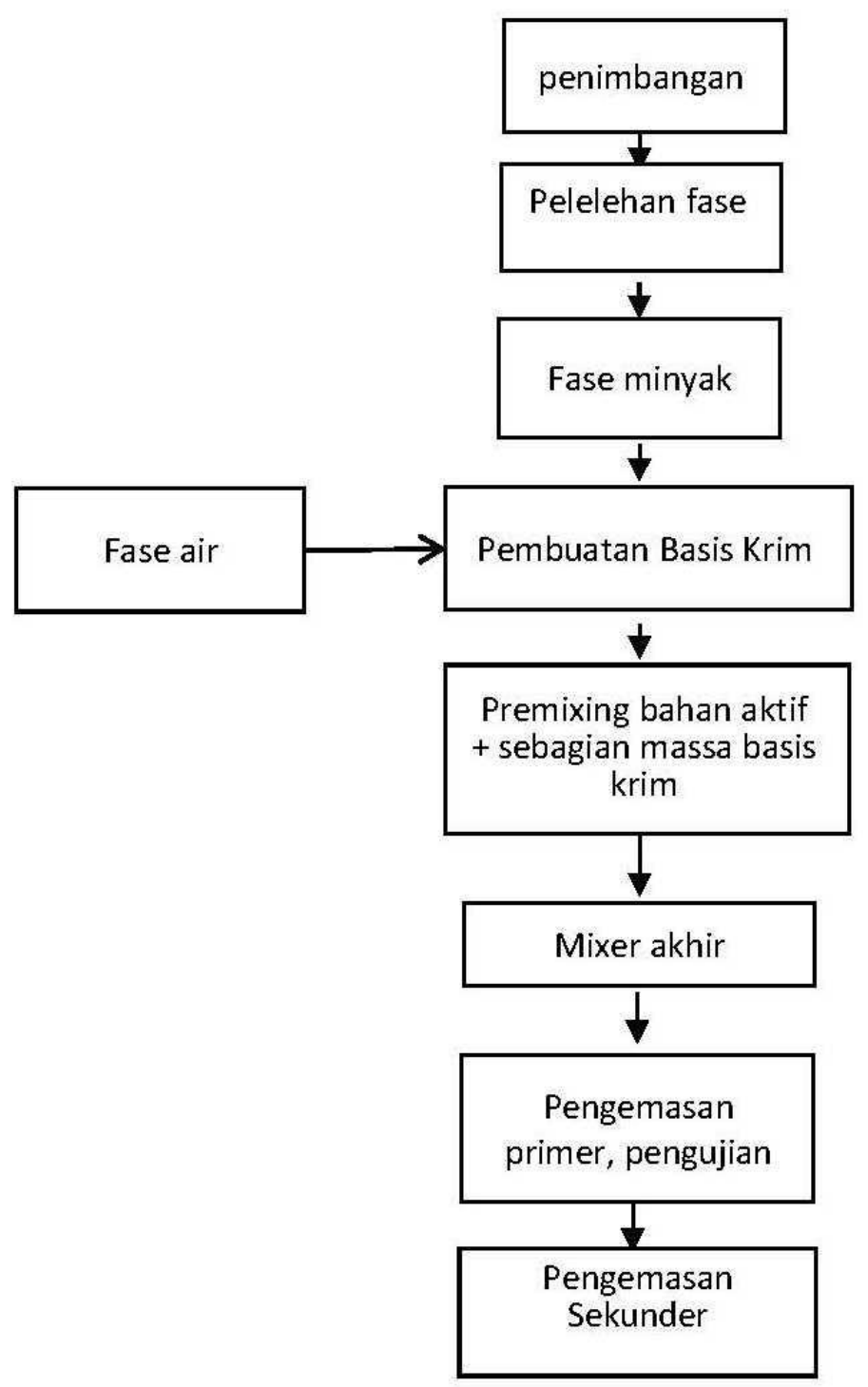

Gambar 1. Alur proses pembuatan produk mikonazol nitrat 2\% 
air, dimana salah satu sebagai fase eksternal dan yang lain sebagai fase internal [7]. Krim mikonazol nitrat $2 \%$ dibuat dari dua fase yaitu fase minyak dan air. Fase minyak dibuat di dalam tangki minyak dan fase air dibuat di tangki air. Fase minyak dan fase air ditransfer melalui pipa ke dalam tangki utama untuk dilakukan pencampuran akhir dengan kondisi vakum.

Masa krim yang sudah tercampur kemudian dilakukan uji produk oleh bagian pengawasan mutu untuk mengecek kesesuaian masa pencampuran dengan spesifikasinya. Masa krim dinyatakan rilis apabila sesuai dengan spesifikasinya, setelah itu dapat dilakukan proses pengemasan primer. Pengemasan primer masa krim mikonazol nitrat $2 \%$ menggunakan mesin pengemas semiotomatik. Pada penelitian ini obyek utama pengukuran efektivitas mesin (OEE) adalah pada proses pengemasan primer menggunakan mesin ini. Pengemasan primer krim mikonazol nitrat 2\% menggunakan dua mesin pengisi krim ke dalam tube untuk menghasilkan produk semisolid mikonazol nitrat 2\% (Gambar 2).

\subsection{Pengumpulan data}

Penelitian dilakukan pada dua mesin pengisi krim ke dalam tube, untuk mengemas produk mikonazol nitrat 2\%. Pengumpulan data dilakukan dengan izin dari PT. Kimia Farma Watudakon sesuai dengan surat izin melakukan penelitian nomor 6088/33/MS/US/IV/2018. Data yang dikumpulkan yaitu data waktu operasi mesin pengisi krim ke tube, waktu berhenti mesin, dan jumlah tube yang dihasilkan dalam tiap batch produk mikonazol nitrat $2 \%$.

Pengumpulan data dalam studi ini meliputi data primer dan data sekunder. Data primer diambil dari pengamatan langsung pada mesin kemudian diisikan pada formulir efektivitas mesin yang telah disediakan. Data sekunder didapat dari data batch record dan formulir pencatatan mesin pe-ngisi krim ke tube. Pengumpulan data dilakukan selama enam bulan (Februari-Juli 2018).

Berdasarkan data yang telah diambil dilakukan perhitungan OEE mesin, kemudian dilakukan perhitungan enam kerugian besar mesin. Enam kerugian besar ini mengacu kepada Lanonne

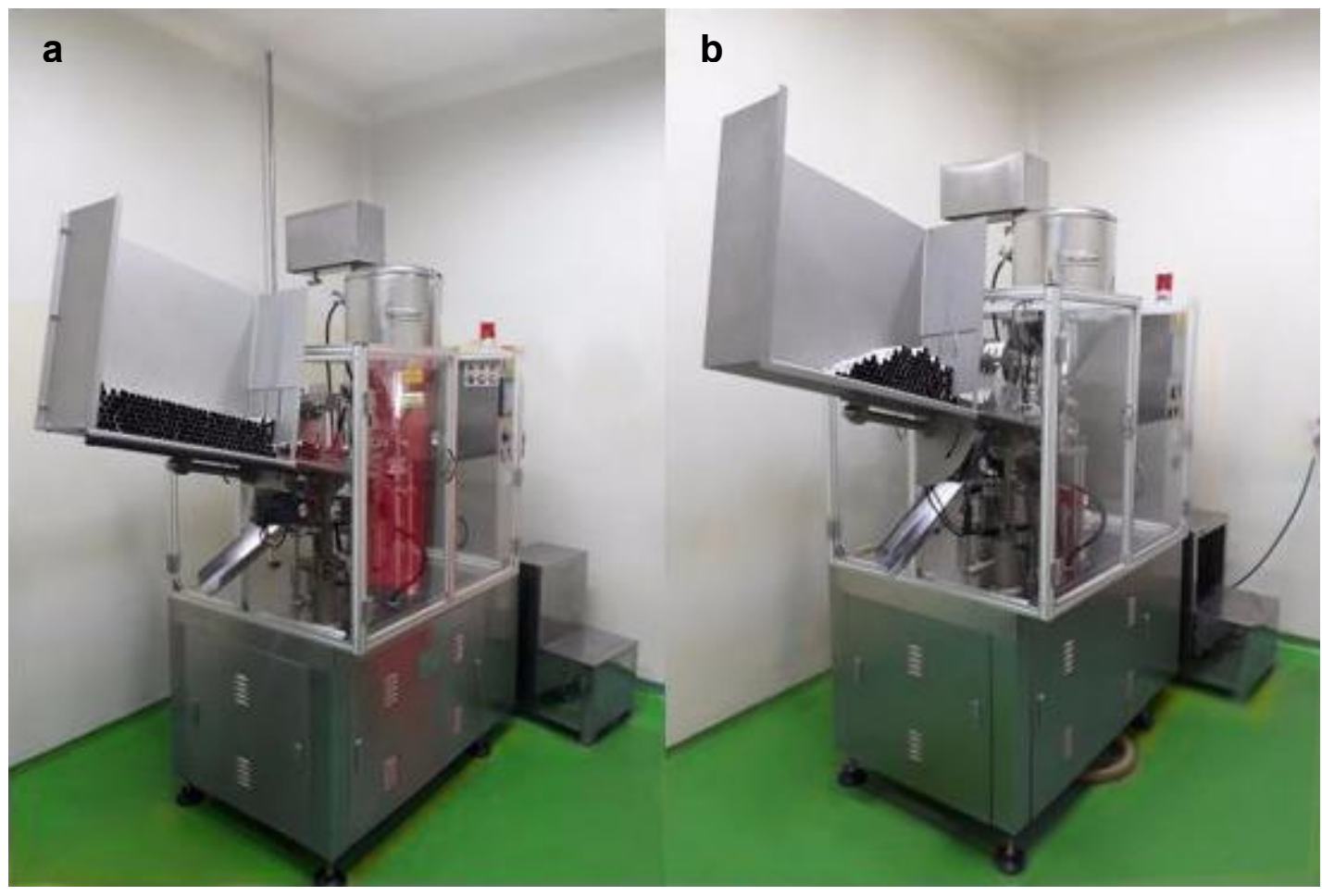

Gambar 2. Mesin pengisi krim ke tube: mesin I (a) mesin II (b) 
dan Nenni [8]. Perhitungan OEE adalah perhitungan efektivitas mesin berdasarkan basis waktu, kerugian-kerugian dihitung dalam satuan waktu. Untuk menghitung nilai kerugian equipment failure yaitu dengan menjumlah total semua waktu pemberhentian tidak terencana pada mesin filling tube I dan II. Perhitungan kerugian setup and adjustment losses yaitu dengan menjumlah total semua waktu penyetelan-penyesuaian pada mesin filling tube I dan II. Perhitungan idling and minor stoppages losses dan reduced speed losses yaitu dengan menjumlah total semua waktu terkait pemberhentian sementara dan kerugian karena kecepatan berkurang. Perhitungan process defect losses dan reduced yield losses yaitu dengan menjumlah total semua waktu cacat prosespengurangan hasil pada mesin filling tube I dan II. Rangkuman perhitungan enam kerugian besar disajikan pada Tabel 1 dan 2 .

Kerugian-kerugian pada mesin dikelompokkan untuk mengetahui kerugian dominan menggunakan diagram Pareto. Diagram sebab akibat dikembangkan untuk menganalisis akar masalah penyebab dari kerugian-kerugian yang terjadi. Dari literatur sangat jelas bahwa analisis dengan diagram Pareto dan diagram sebab akibat merupakan alat penting untuk menganalisa dan mengidentifikasi kerusakan pada proses manufaktur industri [9]. Gambar 3 mengilustrasikan metode dari penelitian ini.

Tabel 1. Perhitungan enam kerugian besar pada mesin pengisi tube I

\begin{tabular}{|c|c|c|c|c|c|c|}
\hline No. & Date & Batch number & $\begin{array}{l}\text { Equipment } \\
\text { failure } \\
\text { (minutes) }\end{array}$ & $\begin{array}{l}\text { Setup and } \\
\text { adjustment } \\
\text { losses } \\
\text { (minutes) }\end{array}$ & $\begin{array}{l}\text { Idling and } \\
\text { minor } \\
\text { stoppages } \\
\text { losses- } \\
\text { reduced speed } \\
\text { (minutes) }\end{array}$ & $\begin{array}{l}\text { Defect } \\
\text { losses- } \\
\text { reduced } \\
\text { yield } \\
\text { (minutes) }\end{array}$ \\
\hline 1 & $03 / 02 / 2018$ & B80216 W,B 80218W & 20 & 30 & 49,73 & 0,09 \\
\hline 2 & $03 / 02 / 2018$ & B80220 W,B80222W & 30 & 30 & 43,85 & 0,15 \\
\hline 3 & $03 / 02 / 2018$ & B80224W,B 80227W & 30 & 30 & 37,73 & 0,27 \\
\hline 4 & $04 / 02 / 2018$ & B80228W,B80231W & 25 & 25 & 50,33 & 1,02 \\
\hline$\cdots$ & $\ldots \ldots \ldots$ & 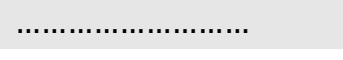 & $\ldots \ldots \ldots \ldots$ & $\ldots \ldots \ldots \ldots$ & $\ldots \ldots \ldots \ldots$ & $\ldots \ldots \ldots \ldots \ldots$ \\
\hline 124 & $10 / 07 / 2018$ & G81915W,G81918W & 0 & 8 & 106,64 & 0,36 \\
\hline Total & & & 634 & 1854 & 9299,60 & 120,11 \\
\hline
\end{tabular}

Tabel 2. Perhitungan enam kerugian besar pada mesin pengisi tube II

\begin{tabular}{|c|c|c|c|c|c|c|}
\hline No. & Date & Batch number & $\begin{array}{l}\text { Equipment } \\
\text { failure } \\
\text { (minutes) }\end{array}$ & $\begin{array}{l}\text { Setup and } \\
\text { adjustment } \\
\text { losses } \\
\text { (minutes) }\end{array}$ & $\begin{array}{l}\text { Idling and } \\
\text { minor } \\
\text { stoppages } \\
\text { losses- } \\
\text { reduced speed } \\
\text { (minutes) }\end{array}$ & $\begin{array}{l}\text { Defect } \\
\text { losses- } \\
\text { reduced } \\
\text { yield } \\
\text { (minutes) }\end{array}$ \\
\hline 1 & 03/02/2018 & B80215W,B80217W & 10 & 20 & 67,45 & 0,18 \\
\hline 2 & 03/02/2018 & B80219W,B80221W & 10 & 20 & 68,44 & 0,47 \\
\hline 3 & $03 / 02 / 2018$ & B80223W,B80225W & 20 & 20 & 57,82 & 0,45 \\
\hline 4 & $04 / 02 / 2018$ & B80226W,B80229W & 10 & 32 & 55,67 & 0,33 \\
\hline$\ldots$ & $\ldots \ldots \ldots$. & 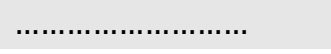 & ….......... & ….......... & ….......... & ….............. \\
\hline 171 & $17 / 07 / 2018$ & G 81923 W & 0 & 5 & 77,51 & 0,22 \\
\hline Total & & & 1160 & 2229 & 13055,09 & 114,51 \\
\hline
\end{tabular}




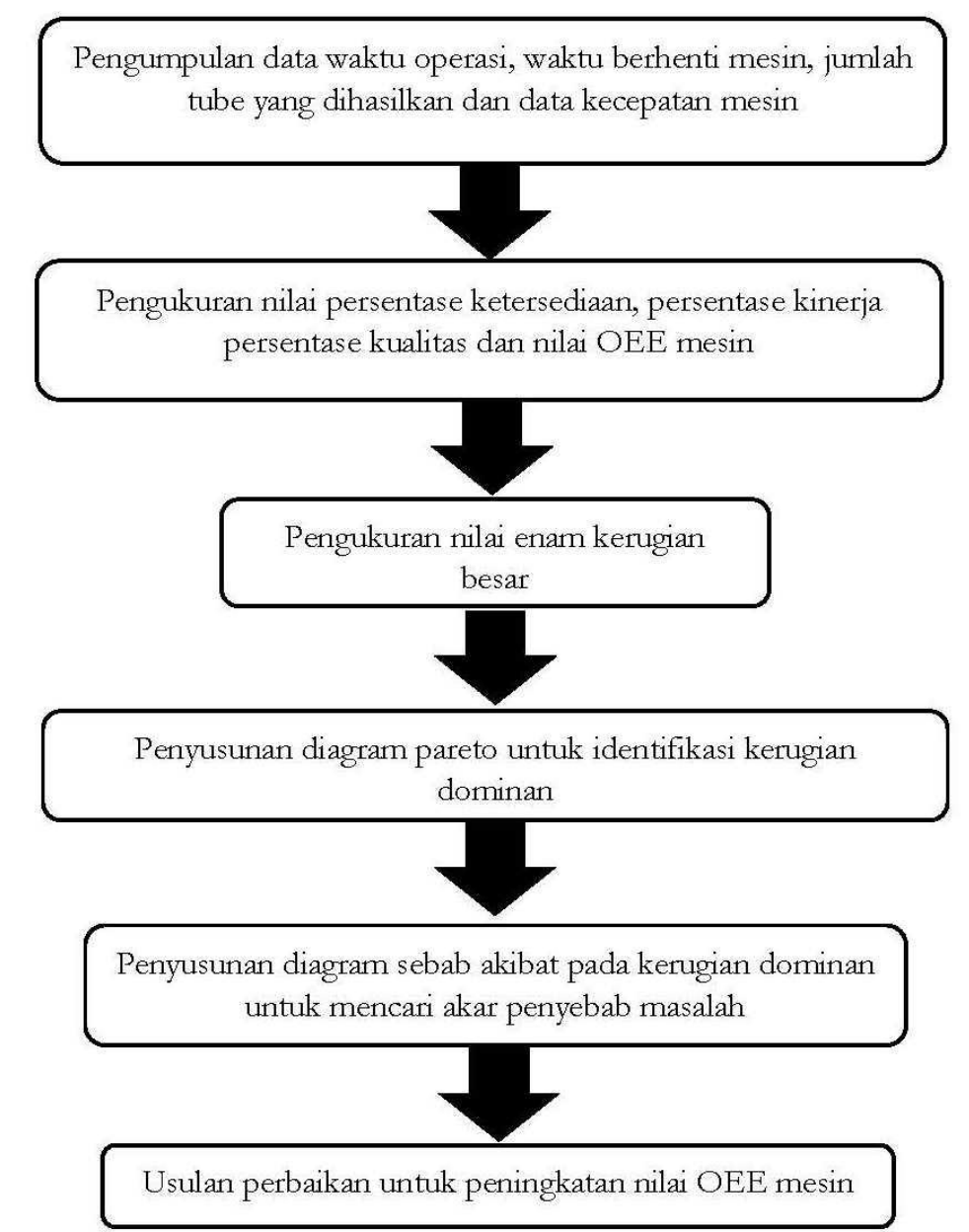

Gambar 3. Metode penelitian

\section{Hasil dan pembahasan}

Perhitungan nilai ketersediaan, kinerja kualitas, dan nilai OEE kedua mesin pengisi krim ke tube disajikan pada Tabel 3. Dari tabel tersebut dapat dilihat bahwa masalah utama pada kedua mesin adalah parameter kinerja mesin. Iddling and minor stoppages dan reduced speed merupakan kerugian pada kinerja mesin [8]. Ini sesuai dengan perhitungan persentase kumulatif enam kerugian yang dihitung pada kedua mesin yang disajikan pada Tabel 4.

Diagram Pareto adalah grafik untuk menampilkan dan mengurutkan suatu data berdasarkan dengan bobot kontribusinya, sehingga dapat mengindentifikasi beberapa item yang memberikan pengaruh maksimal. Diagram ini berguna dalam memprioritaskan fokus perbaikan ke depan pada berbagai masalah mesin [9]. Diagram Pareto digunakan untuk mengetahui faktor domi- nan dari enam kerugian besar yang mempengaruhi nilai OEE pada mesin pengisi krim tube I dan mesin pengisi krim tube II. Grafik diagram Pareto mesin pengisi krim tube I dan mesin pengisi krim tube II disajikan pada Gambar 4 dan 5.

Dari analisis Pareto (Gambar 4 dan 5) terlihat bahwa kerugian terbesar adalah idling minor stoppages-reduced speed, dimana 78,10\% dari total kerugian untuk mesin I dan 78,84\% dari total kerugian untuk mesin II. Perbaikan dapat dilakukan dengan melakukan analisa diagram sebab akibat terhadap faktor terbesar dari enam kerugian besar terhadap nilai OEE mesin pengisi krim tube I dan II. Faktor terbesar dari enam kerugian besar mesin pengisi krim tube I-II adalah idling minor stoppages dan reduced speed.

Mesin pengisi krim tube I dan II adalah mesin pengisi krim tube yang identik sehingga diagram sebab akibat dijadikan satu. Diagram sebab akibat adalah alat bantu yang menunjukkan hubu- 
Tabel 3. Nilai OEE kondisi ideal dan nilai pengamatan OEE mesin pengisi krim I-II

\begin{tabular}{cllllll}
\hline No. & Parameter & $\begin{array}{l}\text { Kondisi ideal } \\
\text { peralatan } \\
(\%)\end{array}$ & $\begin{array}{l}\text { Kondisi mesin } \\
\text { pengisi krim I } \\
\mathbf{( \% )}\end{array}$ & Keterangan & $\begin{array}{l}\text { Kondisi mesin } \\
\text { pengisi krim II } \\
\mathbf{( \% )}\end{array}$ & Keterangan \\
\hline 1. & Ketersediaan & $>90$ & 94,89 & Ideal & 94,91 & Ideal \\
\hline 2. & Kinerja & $>95$ & 77,76 & Tidak ideal & 78,08 & Tidak ideal \\
\hline 3. & Kualitas & $>99$ & 99,64 & Ideal & 99,77 & Ideal \\
\hline 4. & OEE & $>85$ & 73,38 & Tidak ideal & 73,82 & Tidak ideal \\
\hline
\end{tabular}

Tabel 4. Persentase kumulatif enam kerugian besar mesin pengisi tube I-II periode Februari-Juli 2018

\begin{tabular}{llllllll}
\hline No. & $\begin{array}{l}\text { Enam kerugian } \\
\text { besar }\end{array}$ & $\begin{array}{l}\text { Total Waktu } \\
\text { (menit) }\end{array}$ & & $\begin{array}{l}\text { Persentase } \\
\text { (\%) }\end{array}$ & \multicolumn{3}{l}{$\begin{array}{l}\text { Persentase kumulatif } \\
\text { (\%) }\end{array}$} \\
\cline { 3 - 7 } & Mesin I & Mesin II & Mesin I & Mesin II & Mesin I & Mesin II \\
\hline 1 & $\begin{array}{l}\text { Equipment failure } \\
2\end{array}$ & 634 & 1160 & 5,32 & 7,01 & 5,32 & 7,01 \\
\hline $\begin{array}{l}\text { Setup and adjustment } \\
\text { losses }\end{array}$ & 1854 & 2229 & 15,57 & 13,46 & 20,89 & 20,47 \\
\hline 3 & $\begin{array}{l}\text { Idling and minor } \\
\text { stoppages losses }\end{array}$ & 9299,6 & 13055,09 & & & & \\
\hline 4 & Reduced speed losses & & & & & & \\
\hline 5 & Process defect losses & 120,11 & 114,51 & & & & \\
\hline 6 & Reduced yield losses & & & 1,01 & 0,69 & 100,00 & 100,00 \\
\hline & Total & 11907,71 & 16558,6 & 100 & 100 & & \\
\hline
\end{tabular}

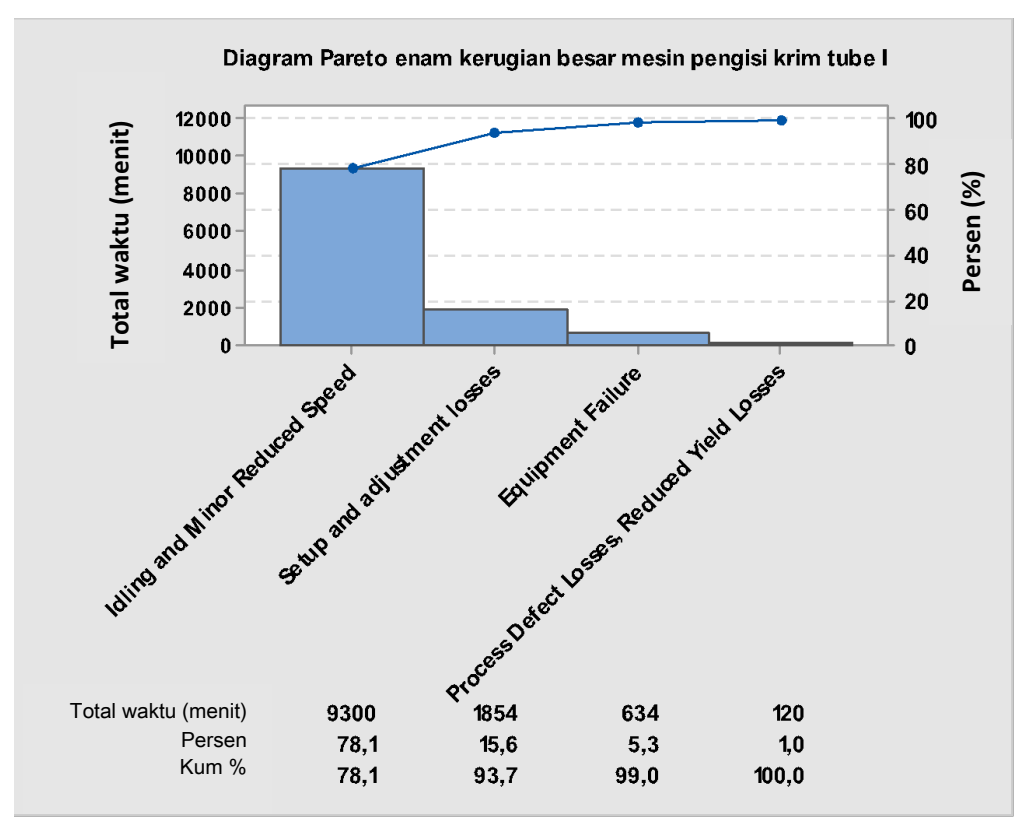

Gambar 4. Diagram Pareto enam kerugian besar mesin pengisi krim tube I 


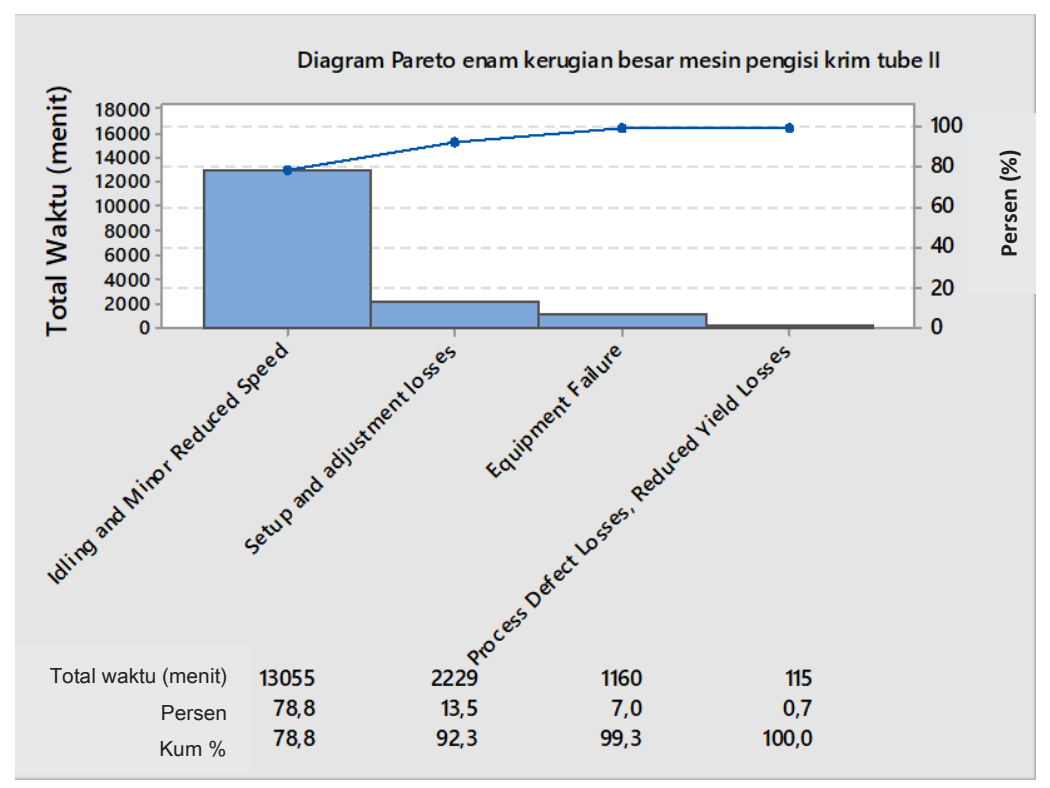

Gambar 5. Diagram Pareto enam kerugian besar mesin pengisi krim tube II

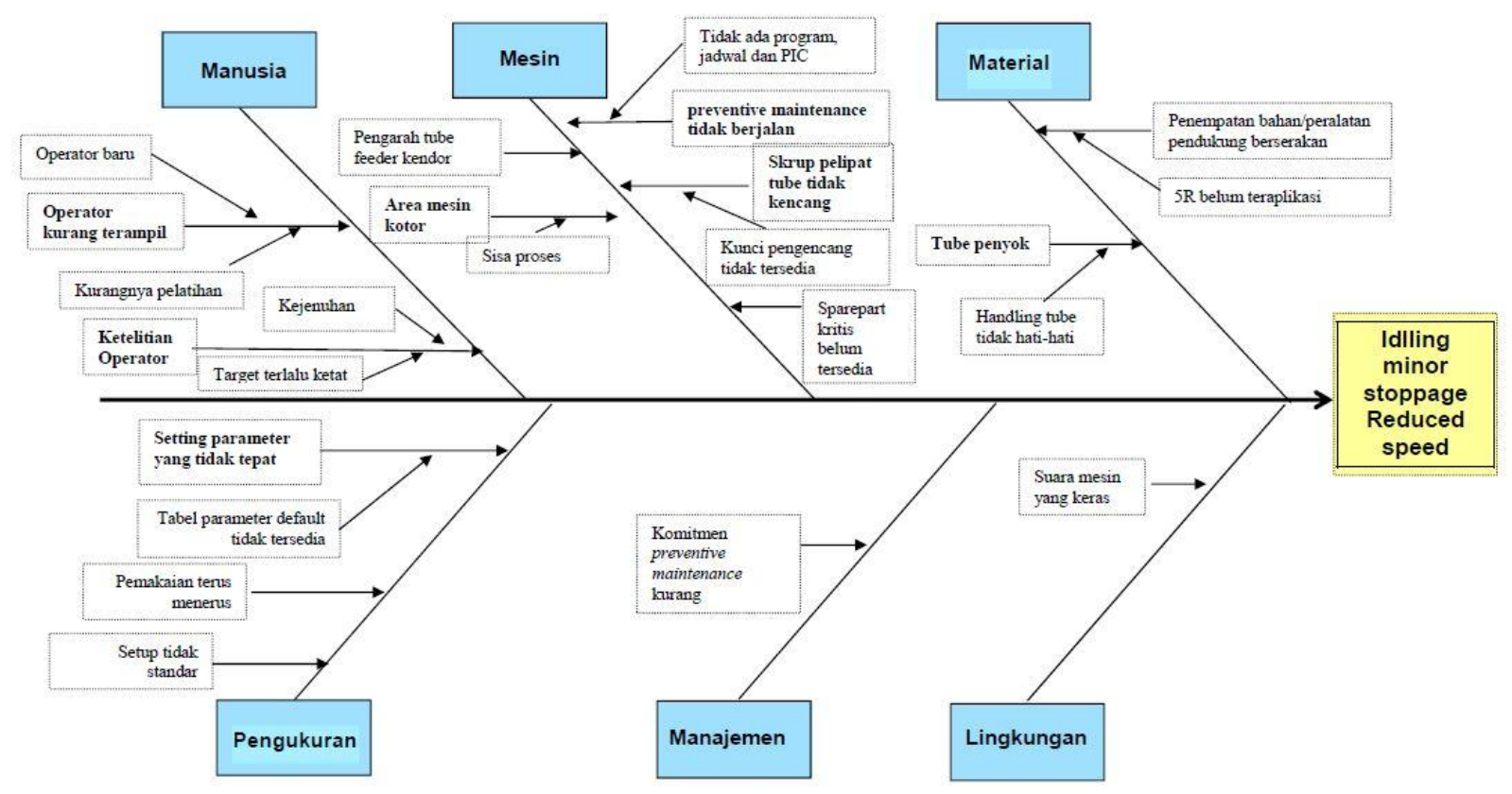

Gambar 6. Diagram sebab akibat untuk idling minor dan stoppage reduced speed mesin pengisi krim tube I dan II

ngan sistematik antara sebuah hasil atau indikasi gejala dan penyebab kemungkinannya. Diagram ini adalah alat bantu yang sederhana dan sangat efektif sebagai bagian dari analisis akar penyebab masalah [10]. Semua penyebab kemudian dimasukkan ke dalam kategori penyebab terbesar. Setelah ditemukan masalah utama diagram sebab akibat dikembangkan untuk mencari penyebabpenyebab kecil pendukung dari masalah utama.

Analisa dilakukan dengan pengamatan lang- sung ke lapangan dan melakukan brainstorming terhadap operator terkait, pelaksana teknik, dan supervisor. Brainstorming pada personil terkait adalah salah satu cara pencarian akar masalah menggunakan diagram sebab akibat [10]. Brainstorming dan diskusi dilakukan untuk menemukan akar masalah dari iddling and minor stoppage menggunakan diagram sebab akibat. Hasil brainstorming diagram sebab akibat ditunjukkan oleh Gambar 6. Analisa akar masalah menggunakan 
Tabel 5. Analisa penyebab dan usulan perbaikan idling minor stoppage-reduced speed

\begin{tabular}{|c|c|c|}
\hline Faktor & Faktor penyebab & Usulan perbaikan \\
\hline \multirow[t]{2}{*}{ Manusia } & Operator kurang terampil & $\begin{array}{l}\text { Melakukan pelatihan dan evaluasi kepada operator } \\
\text { tentang pengoperasian mesin secara berkala }\end{array}$ \\
\hline & Ketelitian operator & Melakukan rotasi pasangan operator secara berkala \\
\hline \multirow[t]{4}{*}{ Mesin } & $\begin{array}{l}\text { Preventive maintenance tidak } \\
\text { berjalan }\end{array}$ & $\begin{array}{l}\text { Bekerja sama dengan bagian teknik untuk menjadwalkan } \\
\text { program preventive maintenance }\end{array}$ \\
\hline & Skrup pelipat tube tidak kencang & Menyediakan kunci pengencang tiap ruangan \\
\hline & Pengarah tube feeder kendor & Melakukan pemeriksaan tube feeder secara berkala \\
\hline & Area mesin kotor & Melakukan pembersihan area mesin secara berkala \\
\hline \multirow[t]{2}{*}{ Material } & $\begin{array}{l}\text { Penempatan bahan/peralatan } \\
\text { pendukung berserakan }\end{array}$ & Menegakkan kembali program 5R \\
\hline & Tube penyok & $\begin{array}{l}\text { Handling tube secara hati-hati oleh orang gudang dan } \\
\text { orang produksi; Pemeriksaan dan perbaikan tube sewaktu } \\
\text { penataan tube }\end{array}$ \\
\hline \multirow[t]{3}{*}{ Pengukuran } & Setting parameter tidak tepat & $\begin{array}{l}\text { Melakukan pengkajian ulang dan melengkapi prosedur } \\
\text { pengoperasian mesin dengan tabel parameter default }\end{array}$ \\
\hline & Penggunaan terus menerus & $\begin{array}{l}\text { Waktu khusus berhenti mesin untuk servis dan } \\
\text { pemeriksaan mesin secara berkala }\end{array}$ \\
\hline & Setup tidak standar & $\begin{array}{l}\text { Penyusunan ulang prosedur pengoperasian dengan } \\
\text { dilengkapi cara setup standar yang mudah dipahami }\end{array}$ \\
\hline Manajemen & $\begin{array}{l}\text { Komitmen preventive } \\
\text { maintenance kurang }\end{array}$ & Pengusulan preventive maintenance kepada manajemen \\
\hline Lingkungan & Suara mesin yang keras & Pemakaian tutup telinga peredam suara pada operator. \\
\hline
\end{tabular}

diagram sebab akibat menunjukkan faktor pada manusia yang berkontribusi adalah kurang terampilnya operator yang menjalankan mesin. Ini terjadi karena sebagian operator telah mendapatkan pelatihan dan sebagian lain belum. Faktor pada mesin yang berpengaruh adalah program preventive maintenance tidak berjalan secara periodik sehingga performa mesin tidak terjamin konsistensinya. Faktor material yang berpengaruh adalah penanganan tube aluminium yang alurnya panjang sehingga memperbesar risiko tube penyok. Tube penyok ini mengganggu kinerja mesin karena akan menyumbat masuknya tube ke dalam feeder sehingga menyebabkan kejadian iddling minor stoppages.

Berdasarkan hasil analisa akar masalah menggunakan diagram sebab akibat maka perlu dilakukan perbaikan menyeluruh untuk meningkatkan performa mesin dengan meminimalisasi atau menghilangkan penyebab masalahnya. Sa- ran perbaikan berkaitan dengan faktor penyebab dari akar masalah tingginya iddling minor stoppage-reduced speed yang menyebabkan nilai performance peralatan rendah sehingga berakibat nilai OEE di bawah nilai ideal. Saran-saran perbaikan dirangkum dalam Tabel 5.

\section{Kesimpulan}

Iddling and minor stoppages dan reduced speed adalah masalah paling umum yang ditemukan di mesin pengemasan di industri farmasi. Masalah tersebut harus diminimalkan untuk meningkatkan produktivitas dan efisiensi mesin pengisi krim ke tube. Pada penelitian ini digunakan alat bantu diagram Pareto dan diagram sebab-akibat untuk identifikasi penyebab timbulnya iddling minor stoppages dan reduced speed mesin pengisi krim ke tube. Didapatkan dari diagram Pa- 
reto bahwa idling and minor stoppages loses dan reduced speed losses mencapai 78,10\% untuk mesin I dan 78,84\% untuk mesin II. Analis sebabakibat menunjukkan penyebabnya adalah tidak seragamnya keterampilan operator, pengaturan mesin yang kurang tepat, preventive maintenance kurang optimal, dan penanganan tube aluminium yang tidak maksimal. Berdasarkan akar masalah tersebut dapat diusulkan beberapa saran untuk mengurangi idling minor stopages dan reduced speed untuk meningkatkan efisiensi mesin pengisi krim ke tube.

\section{Acknowledgement}

Penelitian ini didukung oleh PT. Kimia Farma Plant Watudakon. Peneliti mengucapkan terima kasih kepada semua rekan-rekan PT. Kimia Farma yang telah memberikan bantuan dan saran pada penelitian ini.

\section{Daftar Pustaka}

1. Mubarok MF. Laporan Produksi Formulasi PT. Kimia Farma Watudakon. Jombang; 2016.

2. Mubarok MF. Laporan Produksi Formulasi PT.
Kimia Farma Watudakon. Jombang; 2017.

3. Krisdianto I. Rencana Kerja dan Anggaran Produksi PT. Kimia Farma Watudakon. Jombang; 2017.

4. Hedman R, Subramaniyan M, Almström P. Analysis of Critical Factors for Automatic Measurement of OEE. Procedia CIRP. 2016;57:128-33.

5. Raguram R. Implementation of Overall Equipment Effectiveness (OEE). Middle-East Journal of Scientific Research. 2014;20(5):567-76.

6. Tsarouhas P. Improving operation of the croissant production line through overall equipment effectiveness (OEE) A case study. International Journal of Productivity and Performance Management. 2019;68(1):88-108.

7. Niazi SK. Handbook of Pharmaceutical Manufacturing Formulations: Semisolid Products.Florida: CRC Press; 2009.

8. Lannone R, Nenni ME. Managing OEE to optimize factory performance. In: Operations Management. IntechOpen; 2013.

9. Hossen J, Ahmad N, Ali SM. An application of Pareto analysis and cause-and-effect diagram (CED) to examine stoppage losses: a textile case from Bangladesh. The journal of the textile institute. 2017;108(11):2013-20.

10. Barsalou MA. Root Cause Analysis: A Step-By-Step Guide to Using the Right Tool at the Right Time. New York: Productivity Press; 2014. 